\title{
Subjective Well-Being and Psychopathology \\ Symptoms: Mental Health Profiles and their Relations with Academic Achievement in Brazilian Children
}

\author{
Aline Riboli Marasca ${ }^{1}$ (D) Maurício Scopel Hoffmann ${ }^{2,3,4}$ (D) \\ Anelise Reis Gaya ${ }^{5}$ (D) Denise Ruschel Bandeira ${ }^{6}$ (D)
}

Accepted: 14 November 2020 / Published online: 9 January 2021

(C) Springer Nature B.V. 2021

\begin{abstract}
The aim of this study is to examine the differences in children's academic achievement considering their mental health profiles. Previous studies have started to seek those differences. However, it is not clear what are the academic achievement differences considering distinct children's mental health profile. We used a cross-sectional study sample of 273 students from an elementary school (6-11 years of age) in Porto Alegre, Brazil. Mental health profiles were empirically investigated using latent class analysis by combining a subjective well-being measure and a psychopathology symptom screening. Standardized tests and school grades were considered to assess academic achievement. Findings reveal an empirical division of the sample into four mental health groups. The adjusted analysis revealed that the group with a high level of symptoms, despite having high subjective well-being, had lower levels of academic achievement when compared with the other groups, which have low to moderate levels of psychopathology. Present findings support the idea that psychopathology is a detrimental factor for educational achievement regardless of the levels of wellbeing.
\end{abstract}

Keywords Subjective well-being $\cdot$ Psychopathology $\cdot$ Academic achievement $\cdot$ Mental health · Dual-factor model

Mental health is a topic of interest in different areas and has become a concern of multidisciplinary health services. Frequently, research focuses on the presence of psychopathology and psychological problems due to the negative impact of mental disorders (Westerhof and Keyes 2010). In this field, children and adolescents have become a focus of attention because of the associated significant developmental

Aline Riboli Marasca

aline.marasca@gmail.com

Extended author information available on the last page of the article 
problems and possible life-long consequences (Costello and Maughan 2015). Previous work has also investigated protective factors that are able to buffer the impact of psychopathology or prevent its occurrence (Bos et al. 2016; Hoffmann et al. 2016; Trompetter et al. 2017). In this context, studies based on positive psychology frameworks emphasize the role of subjective well-being and its components as a protective psychological resource (Greenspoon and Saklofske 2001; Seligman and Csikszentmihalyi 2000).

In this framework, the absence of mental illness does not determine the experience of subjective well-being, which is a distinct variable with its own indicators (Wang et al. 2011). Previous work has already empirically examined the distinction between the constructs and determined how to discriminate between them, although they are considered to be related and to contribute to the understanding of the concept of mental health (Greenspoon and Saklofske 2001; Keyes 2005). Some of these studies investigated profiles of mental health based on psychopathology measures and subjective well-being. Greenspoon and Saklofske (2001) offered four research groups: high level of psychopathology and low level of subjective well-being; low level of psychopathology and high level of subjective well-being; low level of psychopathology and subjective well-being; and high level of psychopathology and subjective well-being. The advantage of this mental health model is that it makes it possible to identify risk groups. Even in the absence of symptoms, low subjective well-being can become a vulnerability factor (Greenspoon and Saklofske 2001). Similarly, it has been observed that among individuals with a high level of symptoms, those with higher levels of well-being are more likely to improve their condition, providing empirical support for the understanding of subjective well-being as a protective factor (Kelly et al. 2012). Moreover, the model makes it possible to understand mental health using other indicators, not limited to the occurrence of mental disorder (Slade 2010).

This group division, based on symptoms and subjective well-being levels, was used in further investigations and it is known as the dual-factor model of mental health (Antaramian et al. 2010; Lyons et al. 2013). In most studies, the group with the low level of psychopathology and high level of well-being is called the "complete mental health group", while the group with low levels in both conditions is the "risk group" (Wang et al. 2011). Previous work has also named these groups "flourishing" and "vulnerable" (Kelly et al. 2012). The group with a high level of psychopathology and subjective well-being is called "symptomatic but content," and the group with a low level of psychopathology and subjective well-being is recognized as "troubled" or "languishing" (Wang et al. 2011).

However, there is a limitation in studies that propose this division, because there is no previous agreement on which parameters should be used as a cutoff to assign participants to groups (Kim et al. 2014). This decision is based on different resources, such as means, percentile, and T-score (Antaramian et al. 2010; Greenspoon and Saklofske 2001; Suldo and Shaffer 2008). As a consequence, the proportion of individuals in each group can vary widely across studies (Kim et al. 2014). More recent investigations aim to assess the establishment of groups by using empirical analysis (Kim et al. 2018; Rose et al. 2017), although the number of studies with this approach is still insignificant. To date, no studies have been identified that propose this division in Brazilian samples. 


\section{Subjective Well-Being, Psychopathology Symptoms and Academic Achievement}

In school context, measures related to disorders, deficits and disabilities are frequently reported. However, the positive psychology frameworks have emphasized that positive attributes may help the academic success (Huebner et al. 2004). Just as the presence of psychopathological symptoms can negatively impact school performance and engagement (Van der Ende et al. 2016; Esch et al. 2014), subjective well-being and its components can contribute to academic performance (Lyons and Huebner 2016; Marques et al. 2011).

Previous work had established associations between academic performance and the components of subjective well-being in students of different educational levels (Bücker et al. 2018; Suldo et al. 2014). In elementary school children, academic achievement may show a reciprocal association with components of subjective well-being, that is, students with better performance perceive better subjective well-being, just as subjective well-being can be placed as a predictor of academic performance ( $\mathrm{Ng}$ et al. 2015).

The mental health group division descripted by Greenspoon and Saklofske (2001) can also contribute to our understanding on how some individuals achieve better academic outcomes when compared to others. Overall, the complete mental health group has the best performance at school (O'Connor et al. 2018; Suldo and Shaffer 2008). The risk group may achieve results similar to the troubled group and their performance are worse when compared with the complete mental health group (Suldo et al. 2011). In turn, the symptomatic but content group does not experience a decline in school performance over time (Suldo et al. 2011). On similar findings, life satisfaction is described as a major predictor of academic achievement when compared to the affect component of the subjective well-being (Heffner and Antaramian 2016; Ng et al. 2015). However, there is still no consensus in the literature that good levels of subjective wellbeing are a sufficient condition to determine academic success, due to the impact of psychopathology symptoms on the development of individuals which requires careful investigation (O'Connor et al. 2018; Suldo and Shaffer 2008).

\subsection{Present Study}

The purpose of this study is to verify the differences in children's academic achievement considering their mental health profiles. Previous studies that propose the mental health profile division used different parameters as cutoff points. The present study can contribute to this new approach that invest in an empirical analysis for group division. Thus, this is the first study that investigates the mental health profiles in a Brazilian sample, which can collaborate with the understanding of how this model may work in a developing country, considering that in Brazil and other Latin American locations children tend to have high levels of well-being (OECD 2017). Moreover, it is important to understand which variables can contribute to academic achievement, that are not only related to cognition and exclusively the presence of psychopathology.

Our group division will be based on presence of internalizing and externalizing symptoms. Also, life satisfaction will be employed as a measure of subjective wellbeing as it is considered to be an important indicator of well-being, surpassing the immediate effects of life events and mood states (Diener 2013, Diener et al. 2018; 
Gilman and Huebner 2006). In addition, previous work suggests that life satisfaction is a better predictor of academic achievement when compared with the affective component of subjective well-being (Heffner and Antaramian 2016; $\mathrm{Ng}$ et al. 2015).

First, we will analyze the discriminant validity of the constructs related to child subjective well-being and psychopathology symptoms. Second, children's mental health profiles will be empirically investigated, considering the level of subjective well-being and symptoms of psychopathology. Finally, differences in academic achievement will be compared between the determined groups.

\section{Method}

\subsection{Participants}

We used data from a larger study which was designed to analyze the effects of a physical education program on different health indicators in a school sample. The project obtained measures at the beginning and at the end of the school year. The present study proposes a cross-sectional analysis of data of first evaluation at the beginning of the school year. In Brazil, the school year starts at March and it ends in mid-December. Children attend to classes in a four-hour shift during the morning or in the afternoon period.

The present study included 273 students from first to fifth grade of a state-funded elementary school in Porto Alegre, the capital city of Brazil's southernmost state, one of the tenth most populous city in the country. The sample was selected by convenience criteria. All students who met the criteria for the sample composition in the larger study were included. Ages ranged from 6 to 11 years $(\mathrm{M}=8.36, \mathrm{SD}=1.38)$ and $51.6 \%$ of the children were male. Regarding socioeconomic status, $71.9 \%$ belonged to the lower class and $28.1 \%$ to the middle class. Of the students, $58.2 \%$ attended the afternoon shift. Of the total students, $15.7 \%$ were in the first year of school, $17.6 \%$ in the second year, $22.7 \%$ in the third year, $15 \%$ in the fourth year, and $28.9 \%$ in the fifth year.

The Ethics Committee of Universidade Federal do Rio Grande do Sul approved the study. Informed consent was obtained from parents of all research participants, and verbal assent was obtained from the children.

\subsection{Measurements}

\subsubsection{Sociodemographic Data}

First, we used a questionnaire to obtain personal information, specifically child's age and gender. Additionally, socioeconomic level was measured through the questionnaire of the Brazilian Association of Research Companies (ABEP) with criteria validated from 2015. It is a standardized measure that estimates the economic classification of Brazilian families (Kamakura and Mazzon 2016). The items access home conditions (e.g. number of bathrooms in the house, refrigerators and microcomputers), householder education and the provision of public services, specifically piped water and paved street. The higher the sum of the scores, the better the economic classification. 


\subsubsection{Psychopathology Symptoms}

The presence of psychopathology symptoms was accessed by the Strengths and Difficulties Questionnaire (SDQ, Fleitlich et al. 2000). It is a screening measure used to track symptoms of psychiatric disorders. It consists of a 25 -item questionnaire, divided into five subscales of five items: emotional symptoms, conduct problems, hyperactivity, peer relationship problems, and prosocial behavior. The answers are completed by parents on a three-point scale $(0=$ certainly true, $1=$ somewhat true, and $2=$ not true), considering the child's behavior over the past six months. Moreover, the higher the score, the better the mental health. We used the parent-report version, considering it is the only SDQ version translated and adequately adapted to Brazilian context that was suitable for our sample (Fleitlich et al. 2000).

For the present study, we adopted the model proposed by Goodman et al. (2010) which suggests, for non-clinical populations, combining the items of emotional symptoms and peer relationship problems into a subscale of internalizing symptoms, while conduct and hyperactivity problems are brought together in an externalizing subscale. Therefore, prosocial behavior items were excluded from this analysis. In this study, Cronbach's alpha for the total scale was 0.86 ; for the internalizing symptoms subscale was 0.72 and for the externalizing symptoms subscale was 0.85 . Those values were compatible with previous studies that place Cronbach's alpha for Brazilian SDQ parent version between 0.59 and 0.88 (Saur and Loureiro 2012).

\subsubsection{Subjective Well-Being}

Subjective well-being was accessed by investigating its component, life satisfaction. The Multidimensional Life Satisfaction Scale for Children - Brief Version (EMSVC, Oliveira et al. 2019) is a self-report scale designed to assess life satisfaction in children. The brief version is a 32-item scale which provides five dimensions: self (e.g. "I'm happy"), compared self (e.g. "My friends are happier than me"), family (e.g. "My family likes me"), friendship (e.g. "My friends help me when I need"), and school (e.g. "I like to go to school"). The answers were completed by children in a five-point scale ( $1=$ not at all, $2=$ a little, $3=$ somewhat, $4=$ a lot, $5=$ very much). The higher the score, the better the life satisfaction.

Trained researchers accompanied individually students of the first, second and third year of elementary school to complete the scale and to ensure the understanding of the items. The researchers read each item of the EMSVC and the child had to point the answer in a visual analog scale, in order to minimize mistakes or missing data by reading problems. Fourth- and fifth-year students were able to read the items and record the answers on paper by themselves.

Cronbach's alpha for the total scale was 0.824 , which is similar to the finding of the original study (Oliveira et al. 2019). Cronbach's alpha for self subscale was 0.64 , for compared self was 0.62 , for family 0.72 , for friendship 0.73 , and for school 0.72 .

\subsubsection{Academic Achievement}

The School Achievement Test - Second Edition (TDE II, Stein et al. 2019) is a screening tool for broad assessment, consisting of three subtests that investigate basic 
skills involved in academic achievement: reading, writing, and arithmetic. In the present study, only the writing and arithmetic subtests were included because they allow for collective application. The writing subtest consisted of 40 single words that were read by the examiner and needed to be written by the child. Words presented an increasing difficulty. It was used a version for students from first to fourth years of elementary school and a different version for students from fifth to ninth years of elementary school. The arithmetic subtest is composed of 37 calculations. Eleven calculations were orally presented, while the other calculations needed to be solved and recorded on paper. We used the subtest version for students from first to fifth years of elementary school. We considered the total number of correct answers for each subtest.

We also used school grades of students from the third, fourth, and fifth years of elementary school. The values ranged from 0 to 100 , representing the mean of the grades given by teachers across the different subjects.

\subsubsection{Intelligence}

The Raven's Colored Progressive Matrix Test (Angelini et al. 1999) aims to obtain a measure of children's non-verbal intelligence. It is a psychological test, consisting of three series of 12 items (A, Ab, and B) arranged in order of increasing difficulty. The items reveal an incomplete drawing or matrix; the child must choose from six options one that completes the picture correctly.

\subsection{Statistical Analysis}

Descriptive statistics were conducted and data attend criteria for parametric analysis. Confirmatory factor analyses (CFA) and latent class analyses (LCA) were estimated using lavaan (Rosseel et al. 2018) and poLCA packages (Linzer and Lewis 2011) in R (version 3.5.1). Factor analysis used pairwise deletion to deal with missing data.

The analysis consisted of three steps. First, we determined if EMSVC and SDQ measured the same or different constructs (discriminant validity). Second, if they were distinct constructs, we empirically examined the existence of groups of people depending on the levels of EMSVC and SDQ using LCA. Third, if at least two groups emerged, we compared the academic achievement levels between the groups derived from the LCA.

In the first step, we departed from the understanding of the structure of EMSVC and SDQ as reported in previous literature (Goodman et al. 2010; Oliveira et al. 2019). We further validated these separate structures in our sample using CFA (see Supplementary Analysis). To test if the EMSVC and SDQ models are actually distinct, we compared four models: first, a one-factor model, in which an overarching factor explains the variance between EMSVC and SDQ items (Model 1); second, a bifactor model, in which a general factor loaded all items and EMSVC- and SDQ-specific factors loaded their specific items (Model 2); third, an orthogonal two-factor model, using the EMSVC (second-order model, in Supplementary Material) and SDQ modeled at the same time, but with no correlation between them (Model 3); and, fourth, a correlated two-factor model, which was the same as Model 3, except that the general factors of EMSVC and SDQ were allowed to correlate (Model 4, supplementary Fig. 1). The 
model with the best fit indices were used to extract the factor scores for the latent EMSVC and SDQ variables for the next analytical step (LCA) if they were distinct constructs (i.e., Models 3 and 4). A weighted least square mean of approximation estimator was used, with pairwise deletion of missing data. Model fit was assessed using the chi-square test, root mean square error of approximation (RMSEA), comparative fit index (CFI), and Tucker-Lewis index (TLI) test parameters. RMSEA values of 0.08 or less indicate acceptable fit, while values below 0.06 represent good to excellent fit (Hu and Bentler 1999). CFI and TLI values equal to or above 0.90 suggest acceptable fit and values greater than 0.95 indicate good to excellent fit.

As a second step, we used LCA (set from one to six classes) to empirically verify the existence of groups of subjects according to total life satisfaction (EMSVC second order factor) and psychopathology symptoms (SDQ general factor). Model was selected based on higher entropy (DiStefano and Kamphaus 2006) and lower levels of selection criteria. Selection criteria were log-likelihood, likelihood ratio, the Bayesian Information Criterion (BIC; Schwarz 1978) and the adjusted BIC (see Sclove 1987), Bozdogan's consistent Akaike's Information Criterion (cAIC; Bozdogan 1987). They consist of a goodness-of-fit term plus a penalty to control overfitting, and provide a standardized way to balance sensitivity and specificity. We selected the groups from the model with the best fit and entropy.

The determination of the symptom levels of psychopathology and subjective wellbeing, according to the means of the factor scores, was performed using the analysis of variance test (ANOVA), complemented with the Tukey test. The third step consisted of comparing academic achievement among groups with different levels of psychopathology and subjective well-being. We performed a covariance analysis (ANCOVA) and a post hoc Bonferroni to verify that, if adjusted by intelligence, sex and age, the groups would differ in relation to academic achievement.

\section{Results}

Descriptive statistics are shown on Table 1.

SDQ model fit was acceptable for the present dataset $\left(\chi^{2}=275.8, \mathrm{df}=150\right.$, $p<0.001 ; \mathrm{RMSEA}=0.064,90 \% \mathrm{CI}=0.052-0.076 ; \mathrm{CFI}=0.941 ; \mathrm{TLI}=0.925)$. Standardized factor loadings of each SDQ item predicted by the general,

Table 2 Fit indices and entropy for LCA models

\begin{tabular}{llllllr}
\hline & Loglikelihood & BIC & aBIC & cAIC & Likelihood Ratio & Entropy \\
\hline Model 1 & -8277.105 & $17,409.96$ & $16,878.10$ & $17,577.96$ & $14,893.65$ & - \\
Model 2 & -7852.354 & $17,421.30$ & $16,354.41$ & $17,758.30$ & $14,044.14$ & 0.969 \\
Model 3 & -7641.033 & $17,859.50$ & $16,257.58$ & $18,365.50$ & $13,621.50$ & 0.975 \\
Model 4 & -7487.682 & $18,413.65$ & $16,276.69$ & $19,088.65$ & $13,314.80$ & 0.985 \\
Model 5 & -7423.881 & $19,146.89$ & $16,474.90$ & $19,990.89$ & $13,187.20$ & 0.975 \\
Model 6 & -7345.147 & $19,850.26$ & $16,643.25$ & $20,863.26$ & $13,029.73$ & - \\
\hline
\end{tabular}

BIC, Bayesian Information Criterion; $a B I C$, Adjusted BIC; $c A I C$, Consistent AIC 
Table 1 Descriptive statistics

\begin{tabular}{lccr}
\hline & $n$ & $M$ & $D P$ \\
\hline SDQ - total scale (factor score) & 203 & 0.06 & 0.70 \\
EMSVC - total scale (factorial score) & 272 & -0.03 & 0.90 \\
& Academic achievement measures & & 0.99 \\
TDE writing (z score) & 268 & 0.00 & 0.99 \\
TDE arithmetic (z score) & 268 & 0.00 & 17.4 \\
School grades (0-100) & 166 & 79.4 & \\
\hline
\end{tabular}

$S D Q$, Strengths and Difficulties Questionnaire; EMSVC, Multidimensional Life Satisfaction Scale for Children Brief Version, TDE, School Performance Test

internalizing and externalizing factors are described in supplementary Table 1 and covariance matrix can be seen in supplementary Table 4 . The general SDQ factor was then extracted for use in the main analysis as the standardized measurement of psychopathology. The EMSVC second-order model presented a good fit $\left(\chi^{2}=528.4\right.$, $\mathrm{df}=459, p<0.001 ; \mathrm{RMSEA}=0.024,90 \% \mathrm{CI}=0.012-0.032 ; \mathrm{CFI}=0.989 ; \mathrm{TLI}=$ 0.989). Standardized factor loadings of each EMSVC item predicted by first order factors and the factor loadings of the overall EMSVC second order factor is described in Supplementary Table 2 and covariance matrix can be seen in Supplementary

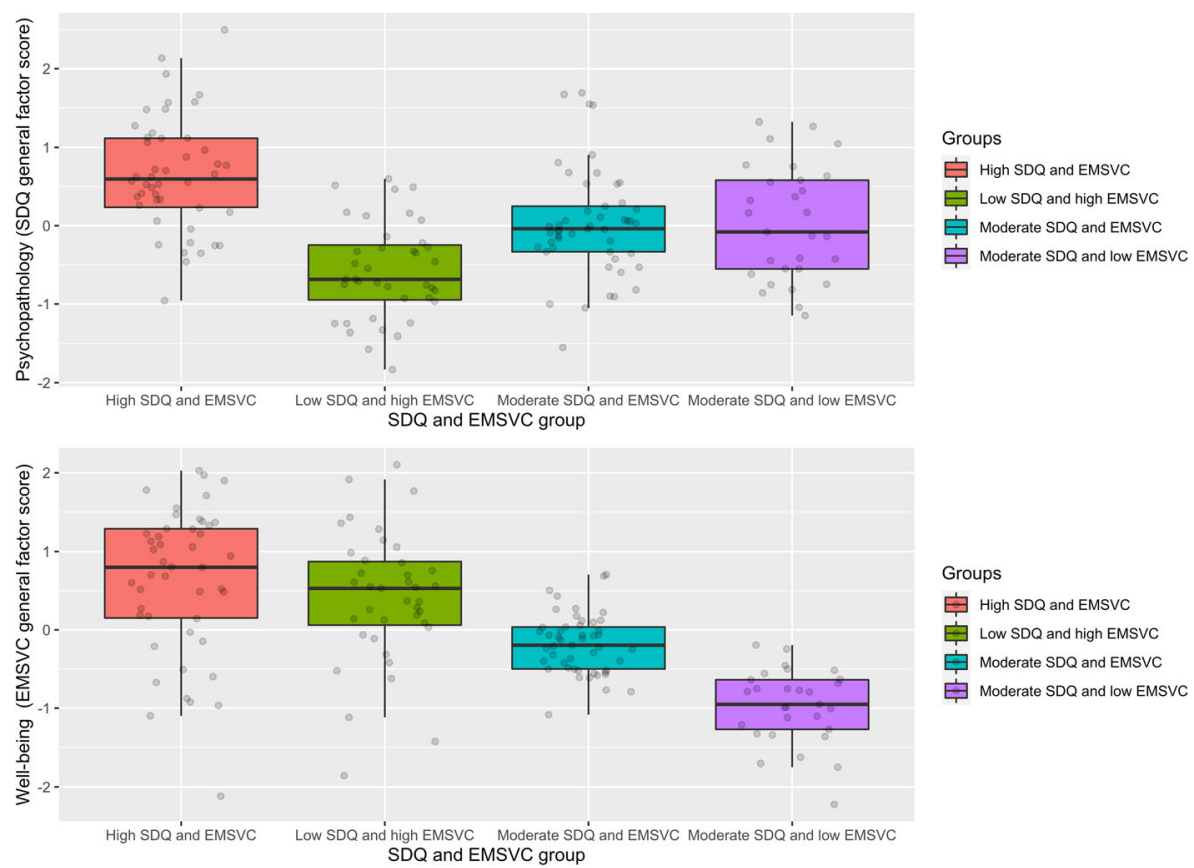

Fig. 1 Group definition according to SDQ and EMSVC means. SDQ, Strength and Difficulties Questionnaire. EMSVC, Multidimensional Life Satisfaction Scale for Children 
Table 5. The factor scores from the second-order factor was extracted as a measure of total life satisfaction and used in the main analysis.

CFA was conducted to evaluate the discriminant validity of subjective well-being and psychopathology. According to the results, Model 4, with two correlated factors showed slightly better fit indices among the tested models (see the model diagram depicted in the Supplementary Fig. 1). It also did not show a statistically significant correlation between the constructs, $\mathrm{r}=-0.063, p=0.423$, indicating their differentiation.

Next, LCA was conducted to verify the groups empirically derived from the sample. The best solution found was that of four classes, which showed higher entropy (0.985) and best in 3 out of 5 fit indices (BIC, aBIC, aCAIC). The parameters of the LCA models are presented in Table 2.

An ANOVA and a Tukey test were performed to determine the differences in group means of the SDQ factor scores and subjective well-being (EMSVC). The groups differed statistically at symptom level $(\mathrm{SDQ}), F(3,159)=22.7, p<0.001$, and wellbeing $($ EMSVC), $F(3,159)=35.4, p<0.001$. These values were set as high, moderate,
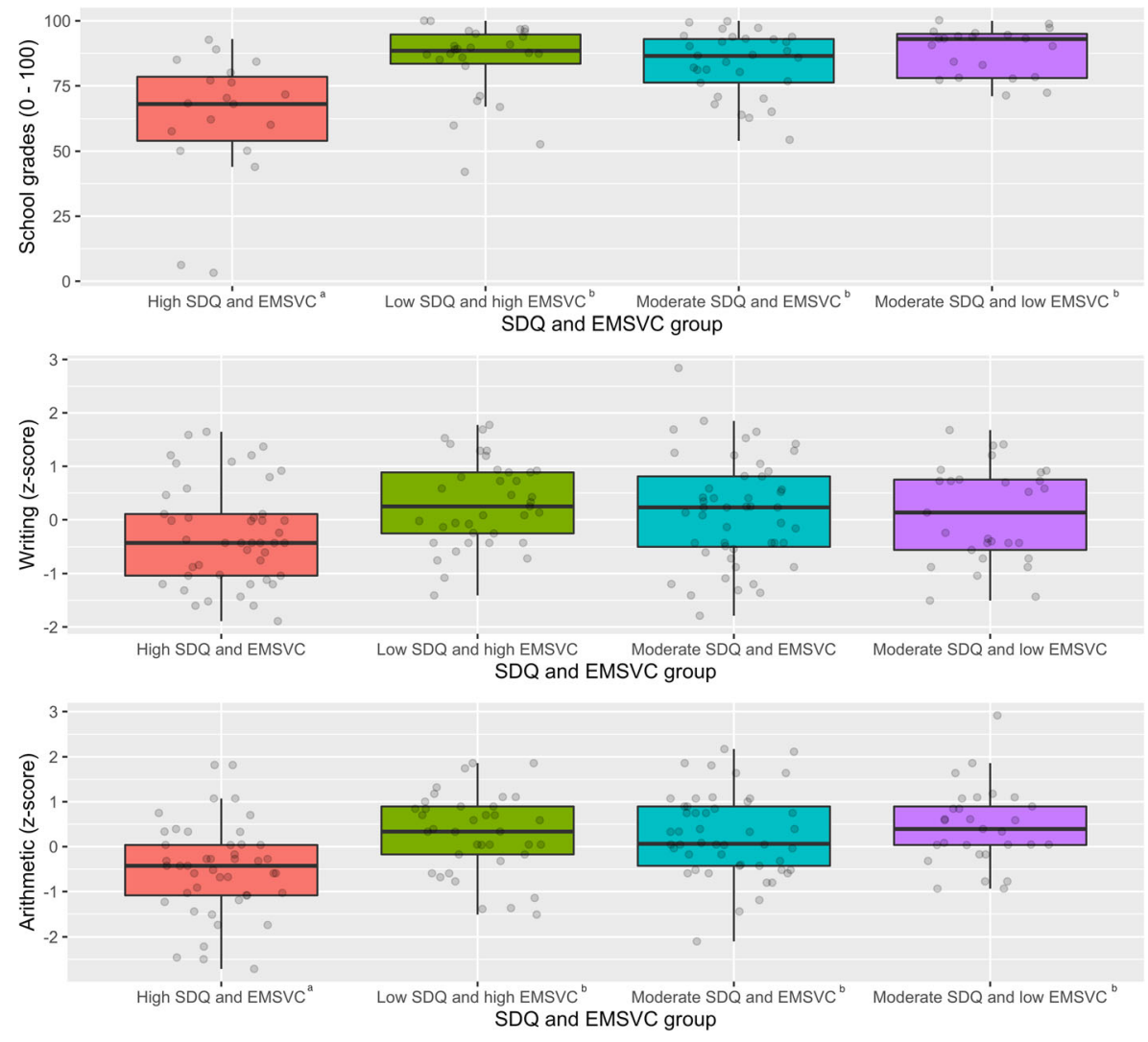

Fig. 2 Differences between academic achievement for groups. Superscript letters were used to identify means that differed significantly in post hoc $(p<0.05)$ in the compared groups. In each line, different letters indicate significantly different averages. SDQ, Strength and Difficulties Questionnaire. EMSVC, Multidimensional Life Satisfaction Scale for Children 
and low, according to the Tukey test significance between groups. The groups were defined as follows: high level of symptoms and subjective well-being (Group 1), moderate level of symptoms and low subjective well-being (Group 2), low level of symptoms and high subjective well-being (Group 3), moderate level of symptoms and subjective well-being (Group 4). Frequency analysis indicated that Group 1 was composed of $28.2 \%$ of the sample, Group 2 of $17.8 \%$, Group 3 of $23.9 \%$, and Group 4 of $30.1 \%$ (Fig. 1 and Supplementary Table 5).

Finally, an ANCOVA and Bonferroni test were conducted in order to determine the differences between groups in performance on the TDE subtests and mean of school grades, controlling for the effect of intelligence, age and sex. We found a statistically significant difference between the groups regarding the mean grade, $F(1,96)=6.15$, $p=0.001$, and performance in the arithmetic subtest, $F(1,159)=4.66, p=0.004$. It was identified that Group 1 differed significantly from the other groups, presenting a lower mean of school grades, $\mathrm{M}=67.55, \mathrm{SD}=3.41$, and a lower performance in the arithmetic subtest, $\mathrm{M}=-0.32, \mathrm{SD}=0.14$. (Fig. 2 and Supplementary Table 6).

\section{Discussion}

This study aimed to verify the differences in children's academic achievement in relation to their mental health profiles, which consider measures of subjective well-being and symptoms of psychopathology. Initially, the discriminant validity of the constructs subjective well-being and psychopathology symptoms were analyzed. Subsequently, mental health profiles were empirically investigated according to the level of the mentioned variables.

According to the results presented, a two-factor model presented the best fit indices, indicating discrimination between the constructs subjective well-being and psychopathology. The distinction between subjective well-being measures and symptoms of psychopathology has already been theoretically suggested and verified empirically (Magalhães and Calheiros 2017; Winzer et al. 2014). It has been observed that the two-factor model has a better fit than models that merge the overarching factors (one-factor and bifactor models), reinforcing the hypothesis that well-being and psychopathology measures represent distinct latent constructs that need to be considered in mental health approaches (Magalhães and Calheiros 2017; Winzer et al. 2014).

Based on this distinction, the proposal of an arbitrary division of mental health profiles according to symptom and well-being levels (Greenspoon and Saklofske 2001) has been questioned, and it has been demanded that new studies provide a deeper investigation into this occurrence (Kim et al. 2017, 2018; Rose et al. 2017). In the present study, LCA was used to empirically analyze the groups proposed by previous work. Results indicated that the best model fit was the four classes model, corroborating the theoretical division into four groups (Greenspoon and Saklofske 2001; Suldo and Shaffer 2008). Differences in factor mean levels between groups allowed classification according to the level of subjective well-being and symptoms of psychopathology, determining the following profiles: high level of symptoms and subjective wellbeing (Group 1), moderate level of symptoms and low subjective well-being 
(Group 2), low symptoms and high subjective well-being (Group 3), and moderate symptoms and subjective well-being (Group 4).

The established groups differ in the level of psychopathology and well-being when compared with previous studies that base the division of the groups on means, standardized scores, or percentiles (Antaramian et al. 2010; Greenspoon and Saklofske 2001; Kelly et al. 2012). On the other hand, this variation has been found in previous work that uses LCA to determine profiles. In a sample of South Korean children, the four-class model presented the best fit and the sample was divided into the following groups: high level of positive psychological characteristics and low level of emotional and behavioral symptoms; moderate level of positive psychological characteristics and emotional and behavioral symptoms; low level of positive and moderate psychological characteristics of emotional and behavioral symptoms; and low level of positive and moderate to high psychological characteristics of emotional and behavioral symptoms (Kim et al. 2018). The authors justify the differences from the original group division based on cultural issues, in which children in South Korea tend to report lower levels of positive psychological characteristics when compared to other nations. Therefore, by empirically examining the occurrence of the groups that best fit the data, different levels of well-being and symptoms can be found, which generated the intermediate groups (moderate levels).

Considering the groups found in the present study, the group with low symptoms and high well-being (Group 3) is similar to the complete mental health group described in the literature. Also, the group with high symptoms and well-being (Group 1) can be identified as "symptomatic but content." In the original model, groups with a low level of well-being would represent some risk to child development, and those with a high level of symptoms could have the greatest impairment (Greenspoon and Saklofske 2001). In our sample, these groups were not clearly identified. However, we found that Groups 2 and 4 have a moderate level of symptoms, and Group 2 has low subjective wellbeing, while Group 4 has a moderate level. For the present sample, we suggest that both groups could be considered a risk category for negative outcomes. Although they do not show symptoms at a high level, their moderate occurrence is still a warning sign for child development. Unlike the study with the South Korean sample (Kim et al. 2018) in which the authors attribute the predominance of low and moderate levels of positive psychological characteristics to cultural issues, in Brazil and other Latin American locations children tend to have high well-being averages (OECD 2017). Therefore, reaching a moderate level may not be a protective factor in this context.

Another point to note is the considerably low level of subjective well-being in Group 2. It is well known that very low levels of well-being tend to be associated with the occurrence of anxiety, depression, and stress symptoms (Bos et al. 2016). In this sample, we question how accurate the parental report is in relation to the presence of symptoms, especially internalizing manifestations. Studies with adolescents inform the low agreement of symptoms reported by parents and children (Van der Meer et al. 2008; Van Roy et al. 2010). In general, parents tend to point to more externalizing symptoms than their children describe. On the other hand, children describe more internalizing problems than their parents and teachers (Borba and Marin 2017). Thus, 
we hypothesized that a similar behavior may occur among younger children, as in the present sample.

Differences between groups regarding their academic achievement were also verified. The group with a high level of psychopathology symptoms and subjective well-being differed significantly from the others, presenting worse mean grades and lower scores in the arithmetic subtest. No differences in academic achievement were found in the other groups. Results of the present study partly disagree with previous work. Suldo and Shaffer (2008) identified that the complete mental health group presented better functionality in school compared with the other groups. However, similar to our findings, students with a high level of symptoms had worse academic achievement, even with a high level of subjective well-being (Suldo and Shaffer 2008). In these cases, well-being may not be a protective variable for negative school outcomes. Antaramian et al. (2010) describe similar results for groups with a high level of symptoms. Apart from the level of subjective well-being, groups with a high level of symptoms had the worst school grades.

Considering our results, we could conclude that the occurrence of a high level of symptoms, apart from the presence of subjective well-being, would be determinant of impairments in school performance. However, a body of evidence stresses the role of well-being as a protective factor, even in individuals with a high level of psychopathology. In longitudinal studies that assess the permanence of individuals in groups over time, it was identified that a group with a high level of psychopathology and well-being had greater instability of belonging compared with other groups (Compton 2016). Individuals in this group were more likely to become part of the complete mental health group compared with individuals with lower well-being, or to stay in the same group without the worsening of well-being or psychopathology (Compton 2016; Kelly et al. 2012). In terms of academic achievement, even though it had worse school grades compared with the complete mental health group, the group with high symptoms and well-being did not experience a decline in performance over time, unlike the group with a low level of symptoms and well-being (Suldo et al. 2011).

Therefore, caution is needed when interpreting these results about academic achievement in order to avoid disregarding the possible protective effects of subjective well-being in children with high symptoms. We hypothesized that, in these cases, subjective well-being may have an indirect effect on its association with academic achievement (Bücker et al., 2018). Other studies that analyze indirect effects of the subjective well-being components have identified that they may contribute to positive development in the occurrence of psychopathology (Moksnes et al. 2016; Sun and Shek 2013). They suggest the need to verify how these relationships occur in the context of academic achievement. Moreover, in the present study, to determine the groups only the measure of general life satisfaction was used. It is noteworthy that the literature has pointed to the relevance of analyzing life satisfaction from its domains (Casas et al. 2013), and it is possible that specific dimensions may present relationships with academic performance which are as of yet little explored. 


\section{Conclusion}

The results of the present study support the mental health model that includes variables related to psychopathology and subjective well-being as possibly contributing to the identification of risk factors and protection for child development. Until now, there has been a shortage of publications that include data from Brazilian samples for the analysis of mental health profiles. The findings on mental health profiles corroborate some of the results previously presented, contributing to the methodological discussion about the best way to establish these groups.

The present study also provides evidence on the differences in children's school performances according to their membership of each model group. The results highlight the damage caused by the occurrence of high levels of psychopathology symptoms. However, further investigation is required into how subjective wellbeing can act as a protective factor for positive school outcomes in this context. We suggest that further studies could longitudinally follow the school trajectory of the groups to analyze if these benefits tend to occur over time. Moreover, the use of other methods may delineate other forms of interaction of subjective well-being components for cases in which psychopathology is present. Specific analysis of life satisfaction domains may provide additional information to the investigation.

A limitation of this study is the characteristics of the sample, which is restricted to students from one school in south Brazil. Although it is advantageous to collect school grade data from only one school because it ensures greater homogeneity of the measure, the inclusion of students from other locations could contribute to expanding the discussion of the results. Additionally, the present study uses a life satisfaction instrument for the analysis of subjective well-being, based on previous evidence that indicates its relevance to academic achievement. However, it can be considered a limitation because subjective well-being is also formed by an affective component. Finally, indication of the level of symptoms was performed only through parental report, which may limit access, especially to internalizing symptoms. We believe that multiple informant assessment could be used to better understand the data.

Supplementary Information The online version contains supplementary material available at https://doi.org/ 10.1007/s12187-020-09792-y.

Authors' Contribution We certify that all authors participated sufficiently in the work to make them responsible for the content. Material preparation and data collection were performed by Aline Riboli Marasca. Data analysis were performed by Maurício Scopel Hoffmann, Aline Riboli Marasca, and Denise Ruschel Bandeira. The first draft of the manuscript was written by Aline Riboli Marasca and it was critically reviewed by Maurício Scopel Hoffmann, Anelise Reis Gaya and Denise Ruschel Bandeira. All authors commented on previous versions of the manuscript and read and approved the final manuscript.

Funding This work was carried out with the support of The Brazilian National Council for Scientific and Technological Development (CNPq).

Data Availability Not applicable. 


\section{Compliance with Ethical Standards}

Conflict of Interest The authors declare that there is no conflict of interest to disclose in relation to the production of this document.

Ethics Approval and Consent to Participate The study was approved by the Ethics Committee of the Universidade Federal do Rio Grande do Sul (UFRGS; project number 1.814.830/2016) in accordance with the regulations of Resolution 466/12 of the National Health Council of Brazil.

Consent for Publication Written informed consent for the publication of this information was obtained from all participants in this study.

Code Availability Not applicable.

\section{References}

Angelini, A. L., Alves, I. C. B., Custódio, E. M., Duarte, W. F., \& Duarte, J. L. M. (1999). Matrizes Progressivas Coloridas de Raven: Escala especial. Manual. São Paulo: CETEPP.

Antaramian, S. P., Huebner, E. S., Hills, K. J., \& Valois, R. F. (2010). A dual-factor model of mental health: Toward a more comprehensive understanding of youth functioning. American Journal of Orthopsychiatry, 80(4), 462-472. https://doi.org/10.1111/j.1939-0025.2010.01049.x.

Borba, B. M. R., \& Marin, A. H. (2017). Contribuição dos indicadores de problemas emocionais e de comportamento Para o rendimento escolar. Revista Colombiana de Psicología, 26(2), 283-294. https:// doi.org/10.15446/rcp.v26n2.59813.

Bos, E. H., Snippe, E., Jonge, P., \& Jeronimus, B. F. (2016). Preserving subjective wellbeing in the face of psychopathology: Buffering effects of personal strengths and resources. PLoS ONE, 11(3), 1-14. https:// doi.org/10.1371/journal.pone.0150867.

Bozdogan, H. (1987). Model selection and Akaike's information criterion (AIC): The general theory and its analytical extensions. Psychometrika, 52, 345-370. https://doi.org/10.1007/BF02294361.

Bücker, S., Nuraydin, S., Simonsmeier, B. A., Schneider, M., \& Luhmann, M. (2018). Subjective well-being and academic achievement: A meta-analysis. Journal of Research in Personality, 74, 83-94. https://doi. org/10.1016/j.jrp.2018.02.007.

Casas, F., Baltatescu, S., Bertran, I., González, M., \& Hatos, A. (2013). School satisfaction among adolescents: Testing different indicators for its measurement and its relationship with overall life satisfaction and subjective well-being in Romania and Spain. Social Indicators Research, 111, 665-681. https://doi.org/ 10.1007/s11205-012-0025-9.

Compton, A. (2016). Examining the longitudinal stability of a dual-factor model of mental health in early elementary school students (Tese de Doutorado). University of Washington, Seattle, Washington.

Costello, J. E., \& Maughan, B. (2015). Annual research review: Optimal outcomes of child and adolescent mental illness. Journal of Child Psychology and Psychiatry, 56(3), 324-341. https://doi.org/10.1111/jcpp. 12371.Annual.

Diener, E. (2013). The remarkable changes in the science of subjective well-being. Perspectives on Psychological Science, 8(6), 663-666. https://doi.org/10.1177/1745691613507583.

Diener, E., Oishi, S., \& Tay, L. (2018). Advances in subjective well-being research. Nature Human Behaviour, 2(4), 253-260. https://doi.org/10.1038/s41562-018-0307-6.

DiStefano, C., \& Kamphaus, R. W. (2006). Investigating subtypes of child development: A comparison of cluster analysis and latent class cluster analysis in typology creation. Educational and Psychological Measurement, 66, 778-794. https://doi.org/10.1177/0013164405284033.

Esch, P., Bocquet, V., Pull, C., Couffignal, S., Lehnert, T., Graas, M., Fond-Harmant, L., \& Ansseau, M. (2014). The downward spiral of mental disorders and educational attainment: a systematic review on early school leaving. BMC Psychiatry, 14(1). https://doi.org/10.1186/s12888-014-0237-4.

Fleitlich, B., Cortazar, P. G., \& Goodman, R. (2000). Questionário de Capacidades e Dificuldades (SDQ). Infanto - Revista de Neuropsiquiatria da Infância e da Adolescência, 8, 44-50.

Gilman, R., \& Huebner, E. S. (2006). Characteristics of adolescents who report very high life satisfaction. Journal of Youth and Adolescence, 35(3), 311-319. https://doi.org/10.1007/s10964-006-9036-7. 
Goodman, A., Lamping, D., \& Ploubidis, G. (2010). When to use broader internalising and externalising subscales instead of the hypothesised five subscales on the strengths and difficulties questionnaire (SDQ): Data from British parents, teachers and children, 38, 1179-1191. https://doi.org/10.1007/s10802-010-9434-X

Greenspoon, P. J., \& Saklofske, D. H. (2001). Toward an integration of subjective well-being and psychopathology. Social Indicators Research, 54(1), 81-108. https://doi.org/10.1023/A:1007219227883.

Heffner, A. L., \& Antaramian, S. P. (2016). The role of life satisfaction in predicting student engagement and achievement. Journal of Happiness Studies, 17(4), 1681-1701. https://doi.org/10.1007/s10902-015-9665-1.

Hoffmann, M. S., Leibenluft, E., Stringaris, A., Manfro, G. G., Miguel, E. C., Rohde, L. A., \& Salum, G. A. (2016). Positive attributes buffer the negative associations. Journal of the American Academy of Child \& Adolescent Psychiatry, 55(1), 47-53. https://doi.org/10.1016/j.jaac.2015.10.013.

Hu, L., \& Bentler, P. M. (1999). Cutoff criteria for fit indexes in covariance structure analysis: Conventional criteria versus new alternatives. Structural Equation Modeling: A Multidisciplinary Journal, 6(1), 1-55. https://doi.org/10.1080/10705519909540118.

Huebner, E. S., Suldo, S. M., Smith, L. C., \& McKnight, C. G. (2004). Life satisfaction in children and youth: Empirical foundations and implications for school psychologists. Psychology in the Schools, 41(1), 8193. https://doi.org/10.1002/pits.10140.

Kamakura, W., \& Mazzon, J. A. (2016). Critérios de estratificação e comparação de classificadores socioeconômicos no Brasil. Revista de Administração de Empresas, 56(1), 55-70. https://doi.org/10. 1590/S0034-759020160106.

Kelly, R. M., Hills, K. J., Huebner, E. S., \& McQuillin, S. D. (2012). The longitudinal stability and dynamics of group membership in the dual-factor model of mental health: Psychosocial predictors of mental health. Canadian Journal Od School Psychology, 27(4), 337-355. https://doi.org/10.1177/0829573512458505.

Keyes, C. L. M. (2005). Mental illness and/or mental health? Investigating axioms of the complete state model of health. Journal of Consulting and Clinical Psychology, 73(3), 539-548. https://doi.org/10.1037/0022006X.73.3.539.

Kim, E., Furlong, M. J., Dowdy, E., \& Felix, D. E. (2014). Exploring the relative contributions of the strength and distress components of dual-factor complete mental health screening. Canadian Journal of School Psychology, 29, 127-140. https://doi.org/10.1177/0829573514529567.

Kim, E., Dowdy, E., Furlong, M., \& You, S. (2017). Mental health profiles and quality of life among Korean adolescents. School Psychology International, 38(1), 98-116. https://doi.org/10.1177/0143034316682296.

Kim, E., Dowdy, E., Furlong, M., \& You, S. (2018). Complete mental health screening: Psychological strengths and life satisfaction in Korean students. Child Indicators Research., 12, 901-915. https://doi. org/10.1007/s12187-018-9561-4.

Linzer, D. A., \& Lewis, J. B. (2011). poLCA: A R package for polytomous variable latent class analysis. Journal of Statistical Software, 42, 1-29.

Lyons, M. D., Huebner, E. S., \& Hills, K. J. (2013). The dual-factor model of mental health: A short-term longitudinal study of school-related outcomes. Social Indicators Research, 114(2), 549-565.

Lyons, M. D., \& Huebner, E. S. (2016). Academic characteristics of early adolescents with higher levels of life satisfaction. Applied Research in Quality of Life, 11(3), 757-771. https://doi.org/10.1007/s11482-0159394-y.

Magalhães, E., \& Calheiros, M. M. (2017). A dual-factor model of mental health and social support: Evidence with adolescents in residential care. Children and Youth Services Review, 79, 442-449. https://doi.org/10. 1016/j.childyouth.2017.06.041.

Marques, S. C., Pais-Ribeiro, J. L., Lopez, S. J. (2011). The role of positive psychology constructs in predicting mental health and academic achievement in children and adolescents: A two-year longitudinal study. Journal of Happiness Studies, 12(6), 1049-1062.

Moksnes, U. K., Lohre, A., Lillefjell, M., Byrne, D. G., \& Haugan, G. (2016). The association between school stress, life satisfaction and depressive symptoms in adolescents: Life satisfaction as a potential mediator. Social Indicators Research, 125(1), 339-357. https://doi.org/10.1007/s11205-014-0842-0.

Ng, Z. J., Huebner, S. E., \& Hills, K. J. (2015). Life satisfaction and academic performance in early adolescents: Evidence for reciprocal association. Journal of School Psychology, 53(6), 479-491. https:// doi.org/10.1016/j.jsp.2015.09.004.

O’Connor, E., O’Connor, M., Gray, S., \& Goldfeld, S. (2018). Profiles of mental health competence and difficulties as predictors of children's early learning. School Mental Health, 10(4), 402-441. https://doi. org/10.1007/s12310-018-9252-9.

OECD. (2017). PISA 2015 results (volume III): Students' well-being (Vol. III). Paris: OECD Publishing. https://doi.org/10.1787/9789264273856-en. 
Oliveira, C. M., Mendonça, E. J., Marasca, A. R., Bandeira, D. R., \& Giacomoni, C. (2019). Escala multidimensional de Satisfação de Vida para Crianças: revisão e normas. Avaliação Psicológica, 18(1), 31-40. https://doi.org/10.15689/ap.2019.1801.15492.04.

Rose, T., Lindsey, M., Xiao, Y., \& Finigan-Carr, S. (2017). Mental health and educational experiences among black youth: A latent class analysis. Journal of Youth and Adolescence, 46, 2321-2340. https://doi.org/10. 1007/s10964-017-0723-3.

Rosseel, Y., Jorgensen, T. D., Oberski, D., Byrnes, J., Vanbrabant, L., Savalei, V., Merkel, E., Hallquist, M., Rhemtulla, M., Katsikatsou, M., Barendse, M., \& Scharf, S. (2018). Lavaan: Latent variable analysis. Retrieved from https://cran.r-project.org/web/packages/lavaan/index.html

Saur, A. M., \& Loureiro, S. R. (2012). Qualidades psicométricas do Questionário de Capacidades e Dificuldades: revisão da literatura. Estudos de Psicologia, 29(4), 619-629. https://doi.org/10.1590/ S0103-166X2012000400016.

Schwarz, G. (1978). Estimating the dimension of a model. Annals of Statistics, 6, 461-464. https://doi.org/10. $1214 / \mathrm{aos} / 1176344136$.

Sclove, L. (1987). Application of model-selection criteria to some problems in multivariate analysis. Psychometrika, 52, 333-343. https://doi.org/10.1007/BF02294360.

Seligman, M. E. P., \& Csikszentmihalyi, M. (2000). Positive psychology: An introduction. American Psychologist, 55(1), 5-14. https://doi.org/10.1037/0003-066X.55.1.5.

Slade, M. (2010). Mental illness and well-being: The central importance of positive psychology and recovery approaches. BMC Health Services Research, 10(26), 1-14. https://doi.org/10.1186/1472-6963-10-26.

Stein, L., Giacomoni, C., \& Fonseca, R. (2019). TDE II: Livro de instruções. Vetor: São Paulo.

Suldo, S. M., \& Shaffer, E. J. (2008). Looking beyond psychopathology: The dual-factor model of mental health in youth. School Psychology Review, 37(1), 52-68.

Suldo, S. M., Thajil, A., \& Ferron, J. (2011). Longitudinal academic outcomes predicted by early adolescents' subjective well-being, psychopathology, and mental health yielded from a dual factor model. The Journal of Positive Psychology, 6(1), 17-30. https://doi.org/10.1080/17439760.2010.536774.

Suldo, S. M., Frank, M. J., Chappel, A. M., Albers, M. M., \& Bateman, L. P. (2014). American high school students' perceptions of determinants of life satisfaction. Social Indicators Research, 118(2), 485-514. https://doi.org/10.1007/s11205-013-0436-2.

Sun, R., \& Shek, D. T. (2013). Longitudinal influences of positive youth development and life satisfaction on problem behaviour among adolescents in Hong Kong. Social Indicators Research, 114, 1171-1197. https://doi.org/10.1007/s11205-012-0196-4.

Trompetter, H. R., Kleine, E., \& Bohlmeijer, E. (2017). Why does positive mental health buffer against psychopathology? An exploratory study on self-compassion as a resilience mechanism and adaptive emotion regulation strategy. Cognitive Therapy and Research, 41, 459-468. https://doi.org/10.1007/ s10608-016-9774-0.

Van der Meer, M., Dixon, A., \& Rose, D. (2008). Parent and child agreement on reports of problem behaviour obtained from a screening questionnaire, the SDQ. European Child \& Adolescent Psychiatry, 17(8), 491497. https://doi.org/10.1007/s00787-008-0691-y.

Van Roy, B., Groholt, B., Heyerdahl, S., \& Clench, A. (2010). Understanding discrepancies in parent-child reporting of emotional and behavioural problems: Effects of relational and socio-demographic factors. BMC Psychiatry, 10(56), 1-12. https://doi.org/10.1186/1471-244X-10-56.

Van der Ende, J., Verhulst, F. C., Tiemeier, H. (2016). The bidirectional pathways between internalizing and externalizing problems and academic performance from 6 to 18 years. Development Psychopathology, 28(3), 855-67. https://doi.org/10.1017/S0954579416000353.

Wang, X., Zhang, D., \& Wang, J. (2011). Dual-factor model of mental health: Surpass the traditional mental health model. Psychology, 2(8), 767-772. https://doi.org/10.4236/psych.2011.28117.

Westerhof, G. J., \& Keyes, C. L. M. (2010). Mental illness and mental health: The two continua model across the lifespan. Journal of Adult Development, 17(2), 110-119. https://doi.org/10.1007/s10804-009-9082-y.

Winzer, R., Lindblad, F., Sorjonen, K., \& Lindberg, L. (2014). Positive versus negative mental health in emerging adulthood: A national cross-sectional survey. BMC Public Health, 14(1238), 1-10. https://doi. org/10.1186/1471-2458-14-1238.

Publisher's Note Springer Nature remains neutral with regard to jurisdictional claims in published maps and institutional affiliations. 


\section{Affiliations}

\section{Aline Riboli Marasca ${ }^{1}$ - Maurício Scopel Hoffmann ${ }^{2,3,4}$ • Anelise Reis Gaya ${ }^{5}$ • Denise Ruschel Bandeira ${ }^{6}$}

1 Institute of Psychology, Universidade Federal do Rio Grande do Sul, Rua Ramiro Barcelos 2600, office 220, Porto Alegre, RS 90035-003, Brazil

2 Neuropsychiatry Department, Universidade Federal de Santa Maria, Santa Maria, Brazil

3 Care Policy and Evaluation Centre, London School of Economics and Political Science, London, UK

4 Graduate Program in Psychiatry and Behavioral Sciences, Universidade Federal do Rio Grande do Sul, Porto Alegre, Brazil

5 School of Physical Education, Physiotherapy and Dance, Universidade Federal do Rio Grande do Sul, Porto Alegre, Brazil

6 Institute of Psychology, Universidade Federal do Rio Grande do Sul, Porto Alegre, Brazil 